\title{
Hemodynamic Characteristics of Abnormal Distri- bution of Pulmonary Blood Flow in Patients with Cardiac Disorders
}

\author{
Hiroshi Sasamoto, M.D., Kiyoshi Hosono, M.D., and \\ Takeyoshi Kunieda, M.D.
}

\section{Summary}

Lung profile scanning using $I^{131}$ labeled macroaggregated albumin ( ${ }^{131}$-MAA) was presented as a quantitative estimation of regional pulmonary blood flow. Distribution index in four parts of the lungs (right, left, upper, and lower) was calculated from the area under MAA-pulmogram.

Characteristics of the impaired distribution of pulmonary arterial flow in cardiac diseases were elevation of U/L ratio which consisted of decrease of blood flow in the lower zone associated with increase in the upper zone.

Increased $\mathrm{U} / \mathrm{L}$ ratio was more characteristic in the patients with left heart failure than with any other specific diseases. From the correlation with hemodynamic variables obtained by the combined right and transseptal left heart catheterizations, increased U/L ratio was found to correlate significantly with left atrial mean pressure. Left atrial mean pressure below $10 \mathrm{~mm} . \mathrm{Hg}$ did not make U/L ratio elevate. When it exceeded $10 \mathrm{~mm} . \mathrm{Hg} \mathrm{U} / \mathrm{L}$ ratio was observed to increase linearly in proportion to the increased left atrial mean pressure. These facts are well explained by the interstitial perivascular edema of the dependent zone in the isolated perfused dog lung which was first introduced by West et al. in 1965. This external counting technique using I $^{131}$-MAA is clinically useful to estimate the severity of various acquired cardiac diseases.

\section{Additional Indexing Words:}

Inverted distribution U/L ratio Left heart failure Left atrial pressure I ${ }^{131}$-MAA Lung profile scanning Distribution index Pulmogram

TT has now been well established that in the normal erect human lung pulmonary blood flow is affected by the gravitational hydrostatic pressure and decreases fairly steadily from the base to the apex, there being virtually no flow at the apex.

First the existence of a gravitational influence on the distribution of pulmonary blood flow was suggested by the results of studies of lobar gas concent-

From the Department of Internal Medicine, School of Medicine, Keio University, Tokyo.

An outline of this study was reported at 5th Annual Meeting of the Japanese Society of Chest Disease in August, 1965, Kumamoto.

Received for publication June 3, 1967. 
ration in 1953 by Martin et al, ${ }^{1)}$ and in 1955 by Mattson et al, ${ }^{2)}$ The recent introduction of radioactive gases into respiratory research has made it possible to measure pulmonary blood flow externally in limited regions of the lung (West, Dollery, ${ }^{3)}$ 1960; Ball et al., ${ }^{4)}$ 1962; Dollery, Gillam, $\left.{ }^{5}\right) 1963$; Anthonisen, Milic-Emili, $\left.{ }^{6}\right)$ 1960). The impaired distribution of pulmonary blood flow, however, has been little known. The patient with severe mitral stenosis or acute left ventricular failure has been found that blood flow to the upper zone exceeds that to the lower zone in the upright lung, since Dollery \& West ${ }^{7)}$ and Dollery \& Gillam $^{5)}$ reported the regional pulmonary blood flow in mitral stenosis using radioactive carbon dioxide in 1960 and radioactive xenon in 1963, respectively.

More recently, radioiodinated macroaggregated albumin (MAA), which was first prepared by Taplin et al. ${ }^{8)}$ in 1963 and found to be safe and effective as a new radiopharmaceutical by Wagner et al. ${ }^{91}$ in 1964 , has been proved to be ideal for measuring regional pulmonary blood flow. Measurement of regional blood flow by this radioisotope scanning is based on the principle that the rate of accumulation of a substance in any region of the body is directly proportional to blood flow in that region. MAA is completely removed from the blood perfusing the area and is not metabolized during the period of observation. Surely regional pulmonary arterial flow distribution estimated with $\mathbf{I}^{\mathbf{1 3 1}}$-MAA intravenous injection method was studied with differential oxygen uptake by Lopez-Majano et al. ${ }^{10}$ in 1964 and excellent agreement of both methods was noted.

In this paper, it is presented that we have studied the distribution of pulmonary blood flow of the erect human lung in various cardiac diseases using MAA lung profile scanning technique which has developed in our laboratory since 1964.11),12) At the same time hemodynamic studies have been consecutively performed using the techniques of the right heart catheterization and the transseptal left heart catheterization. We have seen that upper to lower ratio ( $\mathrm{U} / \mathrm{L}$ ratio) of pulmonary blood flow distribution in the upright lung shows more significant correlation to left atrial mean pressure than to any other hemodynamic variables.

\section{Methods}

Thirty-two patients ranging in age from 22 to 65 years with various cardiac diseases were studied. Eleven patients were in mitral valve disease. Five of them had pure mitral stenosis, 5 with mitral stenosis and insufficiency, and 1 with mitral insufficiency. Three patients had aortic insufficiency. Two patients were in atrial septal defect. Eight patients had been diagnosed as ischemic heart disease including angina pectoris and myocardial infarction. Other 8 patients were in hypertensive heart disease without any known episode of coronary ischemia. 
The distribution of pulmonary arterial blood flow in the upright lung was investigated in all cases by using MAA lung profile scanning technique (described below in detail). Within a few days after lung profile scanning, pulmonary hemodynamics were studied by the routine techniques of the right heart and transseptal left heart catheterizations. Pulmonary artery, pulmonary artery wedge and left atrial pressures were recorded by means of Statham $\mathrm{p}-23 \mathrm{Db}$ strain gauge transducer. Cardiac output was measured by the direct Fick method. Indicator dilution curves were recorded by cuvette densitometer sampling from the brachial artery, after rapid successive injections of coomassie blue were done into the main pulmonary artery and the left atrium. Mean circulation time from the pulmonary artery to the brachial artery and that from the left atrium to the brachial artery were obtained. From subtraction of the latter from the former, true mean pulmonary circulation time was calculated as mean transit time from the pulmonary artery to the left atrium. Cardiothoracic ratio was calculated in the usual manner from the plain chest roentgenogram.

\section{$I^{131-M A A}$ lung profile scanning}

The technique to be used is diagramatically shown in Fig. 1 and 2. The subjects who had previous thyroidal block with Lugol's solution were seated in a chair and about $50 \mu \mathrm{C}$. of $\mathrm{I}^{131}$-labeled macroaggregated albumin ( I $\left.^{131}-\mathrm{MAA}\right)$ was injected intravenously. Since the chest was in a vertical position, this may allow a study of the influence of the gravitational hydrostatic pressure difference on the circulation at the apex and the base of the lungs. Five min. later, he was seated on this scintillation apparatus equipped with two probes with 2 inch sodium iodine

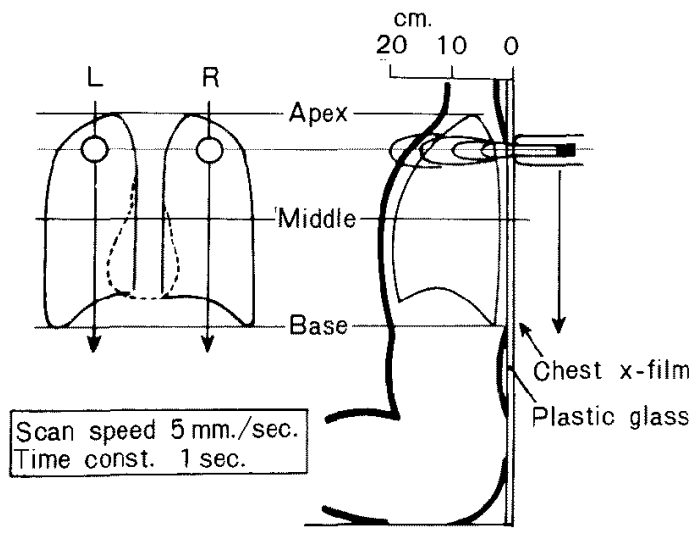

Fig. 1. Schematic illustration of ${ }^{131}$ I-MAA lung profile scanning.

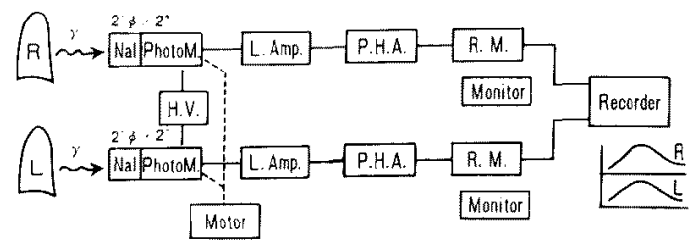

Fig. 2. Block diagram of lung profile scanning. 


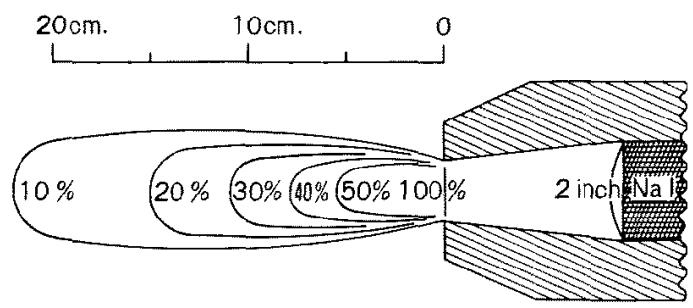

Fig. 3.

crystals and tapered collimators of $90 \mathrm{~mm}$. long with an aperture of $50 \mathrm{~mm}$. and the external orifice of $30 \mathrm{~mm}$. Isoresponse curve of this collimator is illustrated in Fig. 3. Pair of scintillation counters can move automatically by the electric motor from the apex to the base with a speed of $5 \mathrm{~mm}$. per sec.. The bilateral lung was separately scanned along the posterior wall of chest from the apex to the base simultaneously by each counter. Scintillation pulses were recorded on the 2 pen strip chart recorder running with the same speed of $5 \mathrm{~mm}$. a sec. via a rate meter system with time constant of $1 \mathrm{sec}$. Subject's back was marked with lead and anteroposterior chest roentgenogram was taken to make the localization clear.

The curve recorded by this lung profile scanning showing the distribution of pulmonary blood flow along the longitudinal plane has been named MAApulmogram ${ }^{11,12)}$ by the authors. This pulmogram has been described to show the characteristic pattern in various cardiopulmonary disorders. ${ }^{13)}$ MAA pulmogram of the normal erect lung is shown in Fig. 4.

Pulmogram scanned on the midline of each lung expressed rather accurately the radioactive intensity at the region and that had good reproducibility, so that the area under pulmogram could represent regional pulmonary blood flow. There was a good evidence that, on the scan with this apparatus, the sum of the counting efficiency of linear scanning in the upper half of the lung equals experimentally with that in the lower half of the lung, when radioactivity distributes uniformly

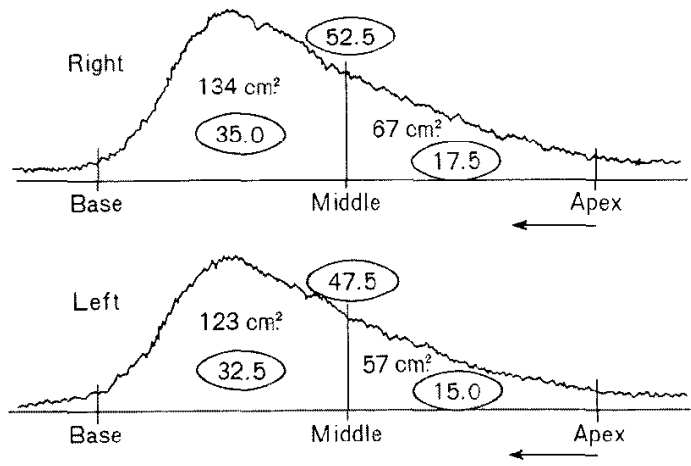

Fig. 4. T.U., 25 years old male.

Normal subject, Normal pattern of MAA pulmogram in the upright lung was demonstrated. Circled letters show each distribution index. U/L ratios were $0.500(67 / 134)$ in right lung, $0.463(57 / 123)$ in left lung, and $0.477(67+57 / 137$ $+123)$ in both lungs, respectively. 
through the lung. From the area under pulmogram, each distribution index of pulmonary blood flow was calculated by planimetric integration as follows:

Right distribution index $=\frac{\int_{a}^{b} f_{R}(x) b x}{\int_{a}^{b} f_{R}(x) d x+\int_{a}^{b} f_{L}(x) d x} \times 100$

Left distribution index $=\frac{\int_{a}^{b} f_{L}(x) d x}{\int_{a}^{b} f_{R}(x) d x+\int_{a}^{b} f_{L}(x) d x} \times 100$

Right upper distribution index $=$ Right distribution index $\times \frac{\int_{a}^{m} f_{R}(x) d x}{\int_{a}^{b} f_{R}(x) b x}$

Right lower distribution index $=$ Right distribution index $\times \frac{\int_{m}^{b} f_{R}(x) d x}{\int_{a}^{b} f_{R}(x) d x}$

Left upper distribution index $=$ Left distribution index $\times \frac{\int_{a}^{m} f_{L}(x) d x}{\int_{a}^{b} f_{L}(x) d x}$

Left lower distribution index $=$ Left distribution index $\times \frac{\int_{m}^{b} f_{L}(x) d x}{\int_{a}^{b} f_{L}(x) d x}$

$\mathrm{U} / \mathrm{L}$ ratio in right lung $=\frac{\text { Right upper distribution index }}{\text { Right lower distribution index }}$

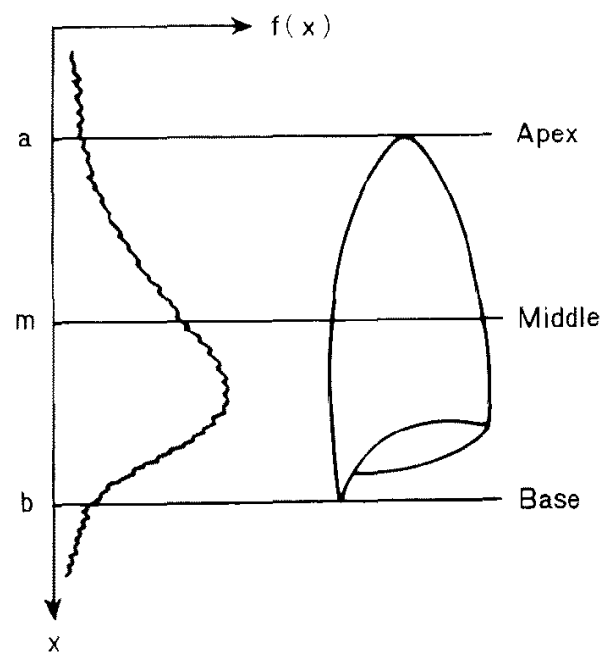

Fig. 5. 
$\mathrm{U} / \mathrm{L}$ ratio in left lung $=\frac{\text { Left upper distribution index }}{\text { Left lower distribution index }}$

$\mathrm{U} / \mathrm{L}$ ratio (both lungs)

$$
=\frac{\text { Right upper distribution index }+ \text { Left upper distribution index }}{\text { Right lower distribution index }+ \text { Left lower distribution index }}
$$

where $f(x)$ is a function of longitudinal direction ( $x$ ) from the apex to the base, namely means pulmogram, $f_{R}(x)$ is $f(x)$ of right lung, $f_{L}(x)$ is $f(x)$ of left lung (see Fig. 5).

In this study, U/L ratio which is the ratio of the upper half lung to the lower half in the distribution of pulmonary arterial blood flow in the upright lung was used.

\section{Results}

Normal values of $\mathrm{U} / \mathrm{L}$ ratio in upright lung obtained from the data of 21 normal healthy subjects were $0.383 \pm 0.094$ (SD) $(0.250-0.650)$ in right lung, $0.411 \pm 0.098(\mathrm{SD})(0.300-0.700)$ in left lung and $0.400 \pm 0.079(\mathrm{SD})(0.300$ 0.600 ) in both lungs. When intravenous MAA injection was carried out, while normal subjects lying supine, supine distribution of pulmonary arterial blood flow were measured since the dynamic distribution of pulmonary arterial flow could be fixed in static state at the time of injection. In this way U/L ratio in the supine lung was obtained. Normal values of $\mathrm{U} / \mathrm{L}$ ratio in supine lung were $0.763 \pm 0.093$ (SD) $(0.650-0.950)$ in right lung, $0.819 \pm 0.081$ (SD) $(0.700-1.000)$ in left lung and $0.781 \pm 0.084$ (SD) $(0.700-0.950)$ in both lungs. Thus these data showed that normal distribution of pulmonary blood flow
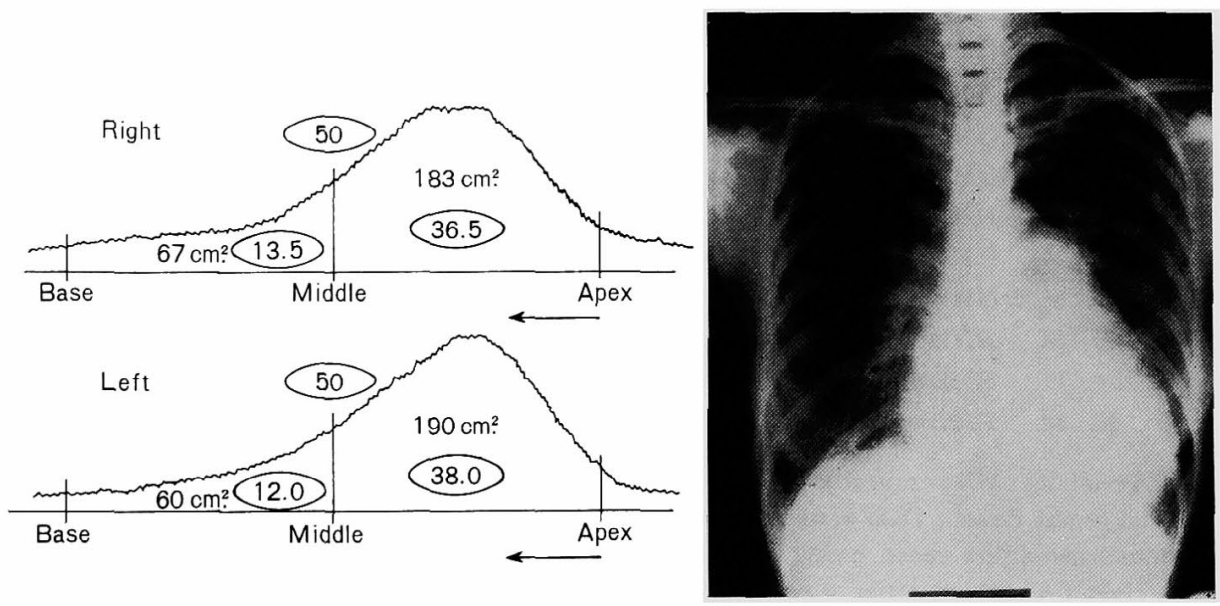

Fig. 6. N.T., 28 years old female. Mitral stenosis with $36.5 \mathrm{~mm} . \mathrm{Hg}$ of left atrial mean pressure. MAA pulmogram in the upright lung showed inverted pattern. Marked increase in $\mathbf{U} / \mathbf{L}$ ratio was observed; 2.73 in right lung, 3.16 in left, and 2.94 in both lungs. 
Table I.

\begin{tabular}{|c|c|c|c|c|c|c|c|c|c|c|c|c|c|}
\hline \multirow[b]{2}{*}{ Name } & \multirow[b]{2}{*}{ Age } & \multirow{2}{*}{ Sex } & \multirow{2}{*}{$\begin{array}{l}\text { Diag- } \\
\text { nosis }\end{array}$} & \multicolumn{2}{|c|}{ U/L Ratio } & \multirow{2}{*}{ PAm } & \multirow{2}{*}{ PAWm } & \multirow{2}{*}{ LAm } & \multirow{2}{*}{ CI } & \multirow{2}{*}{ mpct } & \multirow[b]{2}{*}{ PBV } & \multirow[b]{2}{*}{ CTR } & \multirow{2}{*}{ LHF } \\
\hline & & & & Right & Left $\begin{array}{c}\text { Both } \\
\text { Lungs }\end{array}$ & & & & & & & & \\
\hline $\mathrm{KK}$ & 35 & $\mathbf{F}$ & MS & 0.395 & 0.5170 .450 & 17 & 11 & & 3.52 & & & 47.5 & - \\
\hline IK & 32 & $\mathbf{M}$ & MS & 0.821 & $\begin{array}{lll}0.782 & 0.800\end{array}$ & 38 & & 19 & 2.97 & 4.4 & 217 & 48.7 & - \\
\hline $\mathrm{IM}$ & 30 & $\mathrm{~F}$ & MS & 0.935 & 1.0000 .960 & 16.5 & 12.5 & 15 & 2.28 & 7.6 & 290 & 60.3 & + \\
\hline $\mathrm{HM}$ & 23 & $F$ & MS & 1.180 & 1.3601 .270 & 34 & 27 & 27 & 2.50 & 4.8 & 200 & 50.6 & + \\
\hline IS & 47 & $\mathrm{~F}$ & MS & 1.220 & 1.0401 .130 & 28 & & 20 & 1.75 & 5.2 & 150 & 53.2 & + \\
\hline SH & 34 & F 1 & $\mathrm{MS}+\mathrm{MI}$ & 1.390 & $2.280 \quad 1.750$ & 33 & 33 & 23 & 2.44 & & & 70.3 & + \\
\hline $\mathrm{MU}$ & 29 & $F \quad 1$ & $\mathrm{MS}+\mathrm{MI}$ & 1.040 & $1.122 \quad 1.120$ & 34 & 23 & & 1.86 & & & 56.5 & + \\
\hline NN & 65 & F I & $\mathrm{MS}+\mathrm{MI}$ & 0.912 & $0.930 \quad 0.925$ & 41 & & 23 & 1.19 & 7.3 & 142 & 71.4 & + \\
\hline$Y Y$ & 25 & F I & $\mathrm{MS}+\mathrm{MI}$ & 0.945 & 2.0001 .170 & 25 & & 19.5 & 2.14 & & & 68.4 & + \\
\hline $\mathrm{YH}$ & 48 & M I & $\mathrm{MS}+\mathrm{MI}$ & 0.930 & 1.0401 .000 & 23 & 24 & 20 & 1.71 & 11.3 & 321 & 57.5 & + \\
\hline $\mathrm{HM}$ & 22 & $\mathbf{M}$ & MI & 0.540 & $0.740 \quad 0.610$ & 14 & 6 & 5 & 7.40 & 3.4 & 420 & 44.9 & - \\
\hline $\mathrm{HK}$ & 25 & M & AI & 1.420 & $1.250 \quad 1.330$ & 25 & 18 & 20 & 2.51 & 3.7 & 155 & 53.4 & + \\
\hline $\mathrm{HI}$ & 39 & $\mathrm{M}$ & AI & 0.560 & $\begin{array}{lll}0.560 & 0.560\end{array}$ & 18 & & 13 & 2.23 & 6.2 & 231 & 50.2 & - \\
\hline$M N$ & 33 & M & $\mathrm{AI}$ & 1.120 & 2.0001 .400 & 26 & 18 & & 2.38 & & & 52.0 & + \\
\hline $\mathrm{TI}$ & 23 & $\mathrm{M}$ & ASD & 0.486 & $0.442 \quad 0.464$ & 35 & & 4 & & & & 65.4 & - \\
\hline $\mathrm{KS}$ & 22 & $\mathbf{F}$ & $\mathrm{ASD}$ & 0.654 & $0.812 \quad 0.740$ & 14 & & & 8.65 & & & 55.3 & - \\
\hline $\mathrm{HO}$ & 60 & $\mathrm{M}$ & IHD & 0.830 & $1.185 \quad 0.980$ & 23 & 14 & 15 & 3.97 & 3.7 & 244 & 56.7 & + \\
\hline$Z Y$ & 64 & $\mathrm{M}$ & IHD & 0.375 & 0.5560 .475 & 12 & & & 2.66 & & & 45.2 & - \\
\hline $\mathrm{YH}$ & 37 & $\mathbf{M}$ & IHD & 0.508 & 0.6880 .596 & 14 & 8 & & 2.80 & & & 49.5 & $\ldots$ \\
\hline $\mathrm{KO}$ & 49 & $\mathbf{M}$ & IHD & 0.275 & $0.225 \quad 0.250$ & 11 & 10 & & 2.15 & & & 44.7 & - \\
\hline $\mathrm{KN}$ & 63 & $\mathbf{M}$ & IHD & 0.388 & 0.3520 .370 & 16 & 11 & 7 & 2.10 & 5.5 & 192 & 52.3 & - \\
\hline YU & 55 & $\mathbf{M}$ & IHD & 0.317 & 0.2770 .300 & 6 & 2.5 & & & & & 49.7 & - \\
\hline $\mathrm{TM}$ & 58 & $\mathbf{M}$ & IHD & 0.274 & $0.295 \quad 0.283$ & 18 & 9.5 & 5.5 & 2.76 & 5.8 & 267 & 52.3 & - \\
\hline$M Y$ & 62 & $\mathbf{M}$ & IHD & 0.525 & $0.500 \quad 0.515$ & 10 & 1 & & 3.17 & & & 40.7 & - \\
\hline TK & 44 & $\mathbf{M}$ & HHD & 0.810 & $0.791 \quad 0.800$ & 38 & 10 & & 2.52 & & & 47.4 & + \\
\hline $\mathrm{YT}$ & 60 & $\mathrm{M}$ & HHD & 1.110 & 1.2601 .180 & 29 & & & 5.63 & & & 40.5 & + \\
\hline $\mathrm{TF}$ & 58 & $\mathbf{M}$ & HHD & 0.412 & $0.465 \quad 0.440$ & 15 & 10 & & 2.80 & & & 40.2 & - \\
\hline II & 45 & $\mathbf{M}$ & HHD & 0.858 & 1.0410 .940 & 20 & 14 & 13 & 5.12 & & & 48.2 & + \\
\hline TY & 22 & $\mathrm{M}$ & $\mathrm{HHD}$ & 0.641 & $0.517 \quad 0.580$ & 11 & 1 & & 4.32 & & & 44.7 & - \\
\hline $\mathrm{KS}$ & 59 & $\mathrm{M}$ & HHD & 0.268 & $0.281 \quad 0.273$ & 11 & 6 & & 2.45 & & & 44.9 & - \\
\hline AT & 54 & F & HHD & 0.552 & $0.550 \quad 0.552$ & 10 & 4 & & 4.35 & & & 50.5 & - \\
\hline $\mathrm{YN}$ & 46 & $\mathbf{M}$ & HHD & 0.464 & $0.432 \quad 0.450$ & 15 & 9 & & 2.23 & & & 49.8 & - \\
\hline $\begin{aligned} & \mathrm{Ab} \\
&= \mathrm{atr} \\
&= \mathrm{pu} \\
&(\mathrm{mm} . \\
&= \mathrm{m}\end{aligned}$ & $\begin{array}{l}\text { se } \\
\text { on: }\end{array}$ & tal & $\begin{array}{l}\mathrm{s}: \mathrm{MS}=\mathrm{n} \\
\text { defect ; If } \\
\text { artery mes }\end{array}$ & $\begin{array}{l}\text { ral st } \\
=\text { is } \\
\text { press }\end{array}$ & $\begin{array}{l}\text { enosis; } \mathrm{MI}= \\
\text { schemic heart } \\
\text { sure (mm. } \mathrm{Hg} \text { ) }\end{array}$ & $\begin{array}{l}\text { mit } \\
\text { dise } \\
; \mathrm{P}\end{array}$ & $\begin{array}{l}\mathrm{l} \text { insuffic } \\
\mathrm{e} ; \mathrm{HH} \\
\mathrm{Wm}=\mathrm{p} \\
\mathrm{Ig}) ; \mathrm{CI}\end{array}$ & $\begin{array}{l}\text { iciency; } \\
I D=h y\end{array}$ & $\begin{array}{c}\text { AI } \\
\text { ypert }\end{array}$ & $\begin{array}{l}\text { aorti } \\
\text { sive }\end{array}$ & 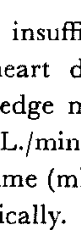 & $\begin{array}{l}\text { ciency } \\
\text { isease; } \\
\text { lean p }\end{array}$ & $\begin{array}{l}\text { ASD } \\
\text { PAm } \\
\text { essure } \\
\text { mpct }\end{array}$ \\
\hline
\end{tabular}


must obviously be affected by the hydrostatic pressure. U/L ratio showed lower value in the upright lung and it increased until it was virtually near 1.00 when the subjects were supine. U/L ratio in normal subjects, however, could not exceed 1.00. In contrast to these distribution patterns, the inverted distribution of pulmonary arterial flow was found in some of cardiac disorders, in which $\mathrm{U} / \mathrm{L}$ ratio could exceed 1.00. Inverted pulmogram showing marked increase in U/L ratio was demonstrated in mitral stenosis with $36.5 \mathrm{~mm}$. $\mathrm{Hg}$ of left atrial mean pressure (Fig. 6). Hemodynamic data from 32 patients with various cardiac diseases were presented in Table I. In Fig. 7, U/L ratio in the upright lung in 21 normal subjects and 32 cardiac diseases was shown. Some of cardiac diseases showed increased U/L ratio. As shown in Table I, in every kind of acquired cardiac diseases such as mitral valve disease, aortic valve disease, ischemic heart disease and hypertensive heart disease, abnormal increase in $U / L$ ratio was observed. Increased $U / L$ ratio was considered not to be disease specific but to reflect the abnormality of pulmonary circulatory dynamics.

Closed circles in Fig. 7 represented the cascs with left heart failure which were assessed clinically with the symptoms of cardiac asthma of orthopnea and

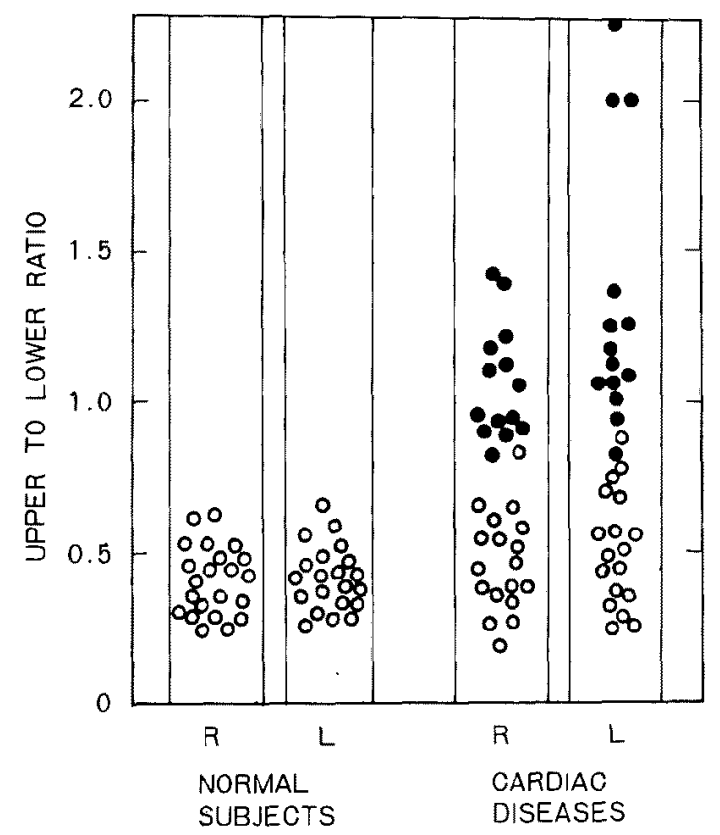

Fig. 7. Comparison of normal subjects and cardiac diseases in $\mathrm{U} / \mathrm{L}$ ratio in each lung (R.= right lung, L.=left lung). There was significant difference between two groups. Especially groups with left heart failure (closed circles) showed increased $\mathbf{U} / \mathbf{L}$ ratio and was distinguished from others. 


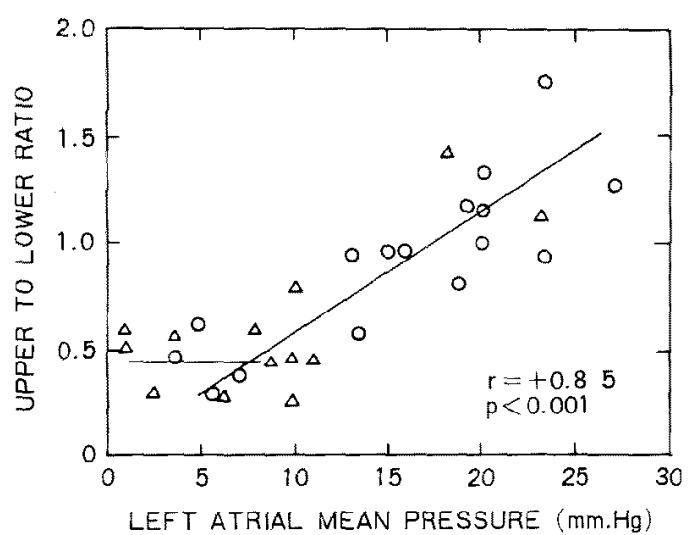

Fig. 8. Relationship between left atrial mean pressure and $U / L$ ratio in the upright lung. Significant correlation was observed $(r=+0.85, p<0.001)$. When left atrial mean pressure was under $10 \mathrm{~mm} . \mathrm{Hg}, \mathrm{U} / \mathrm{L}$ ratio remained normal and did not elevate. Triangles show the cases in which left atrial mean pressure failed to be measured and pulmonary artery wedge mean pressure was employed.

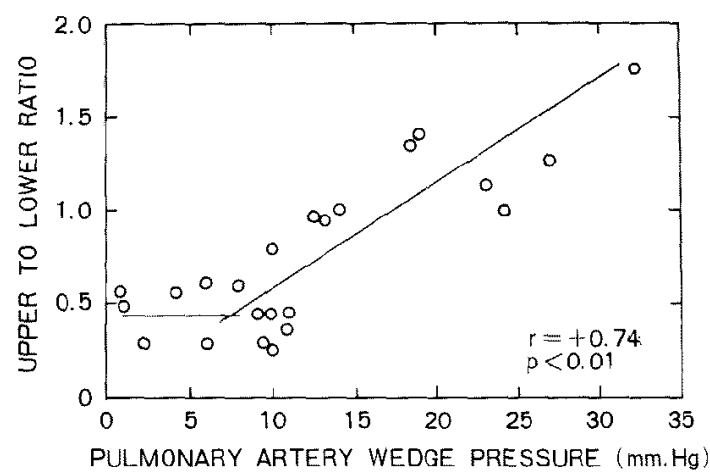

Fig. 9. Relationship between pulmonary artery wedge mean pressure and U/L ratio in the upright lung. Similar correlation to left atrial mean pressure was observed $(r=+0.74, p<0.01)$.

hemosputum or with the episodes of left heart failure. This group was clearly distinguished from another group without left heart failure. Elevation of $\mathrm{U} / \mathrm{L}$ ratio was characteristically noticed in the cases with left heart failure. Correlations of U/L ratio with hemodynamic variables were shown in Fig. 8, 9 and 10.

As observed in Fig. 8, there was a significant correlation between $\mathrm{U} / \mathrm{L}$ ratio and left atrial mean pressure $(r=+0.85, p<0.001)$. Triangle signs in this figure represent pulmonary artery wedge pressure in the cases in which left atrial pressure failed to be measured by the transseptal catheter. The same 


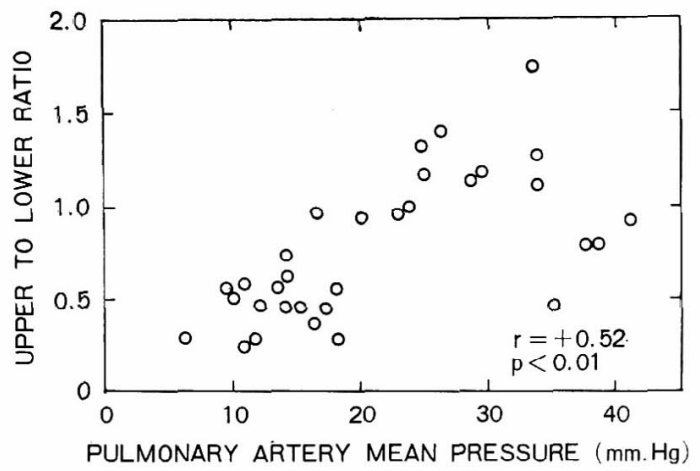

Fig. 10. Relationship between pulmonary artery mean pressure and $\mathrm{U} / \mathrm{L}$ ratio in the upright lung.

correlation was observed in pulmonary artery wedge mean pressure in Fig. 9 $(\mathrm{r}=+0.74, \mathrm{p}<0.01)$.

These results indicate that increase in $\mathrm{U} / \mathrm{L}$ ratio might be linearly proportional to that in left atrial mean pressure. Elevation of $\mathrm{U} / \mathrm{L}$ ratio was not observed until left atrial mean pressure or pulmonary artery wedge mean pressure exceeded $10 \mathrm{~mm} . \mathrm{Hg}$. Less correlation shown in Fig. 10 was observed between $\mathrm{U} / \mathrm{L}$ ratio and pulmonary artery mean pressure $(\mathrm{r}=+0.52, \mathrm{p}<0.01)$. In a 16 year female patient of primary pulmonary hypertension with $60 \mathrm{~mm} . \mathrm{Hg}$ of pulmonary artery mean pressure, $\mathrm{U} / \mathrm{L}$ ratio in the upright lung was 0.835 in right lung, 0.910 in left lung and 0.868 in both lungs, in spite of marked increase in pulmonary artery mean pressure (Fig. 11).
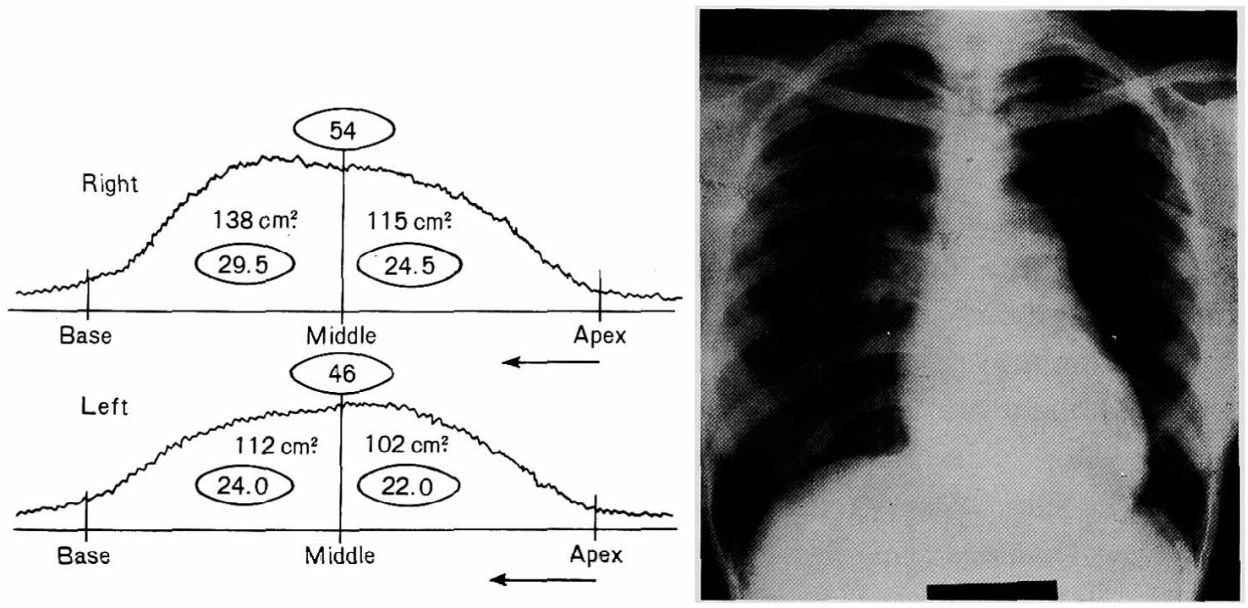

Fig. 11. Y.S., 16 years old female. Primary pulmonary hypertension. Though pulmonary artery mean pressure was elevated to $60 \mathrm{~mm} . \mathrm{Hg}, \mathrm{U} / \mathrm{L}$ ratio in the upright lung was not so increased. $\mathrm{U} / \mathrm{L}$ ratio remained in $\mathbf{0 . 8 6 8 .}$ 


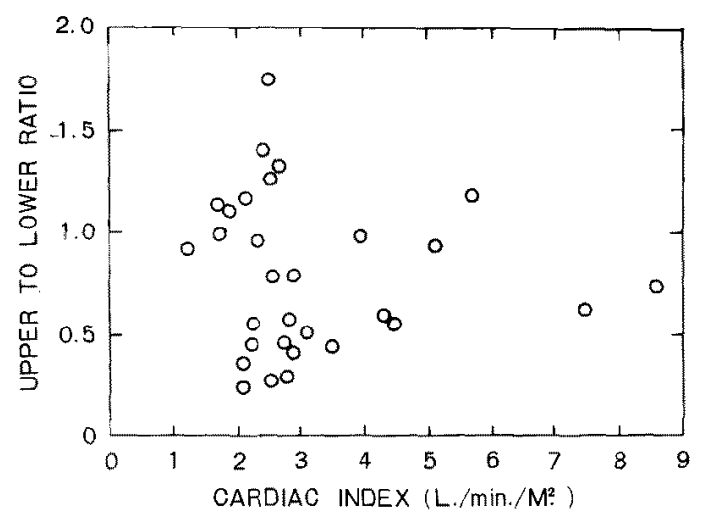

Fig. 12. Relationship between cardiac index and U/L ratio in the upright lung.

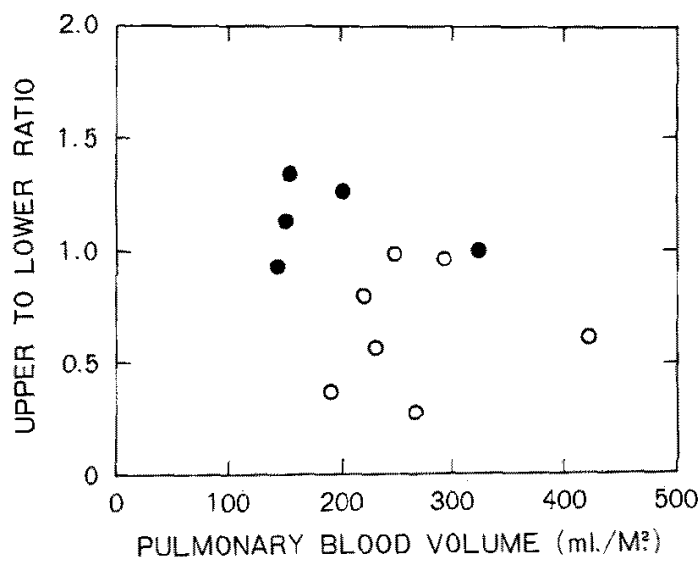

Fig. 13. Relationship between true pulmonary blood volume and U/L ratio in the upright lung. Closed circles were the cases in which left atrial mean pressure equaled or exceeded $20 \mathrm{~mm} . \mathrm{Hg}$.

Cases with marked pulmonary artery pressure, however, showed little change of gravity in the distribution of pulmonary arterial flow between the supine lung and the upright lung. These findings were noticed in the cases with pulmonary arterial hypertension, whether they were postcapillary pulmonary hypertension postcapillary or precapillary pulmonary hypertension. Detail in thesc data would be presented in another article. ${ }^{14)}$ Fig. 12 and 13 showed correlations of $\mathrm{U} / \mathrm{L}$ ratio with cardiac index and true pulmonary blood volume. Inverse correlation was roughly observed. Cardiac diseases with increased $\mathrm{U} / \mathrm{L}$ ratio revealed decreased tendency of cardiac index and pulmonary bload volume. Closed circles in Fig. 13 were the cases equal or 


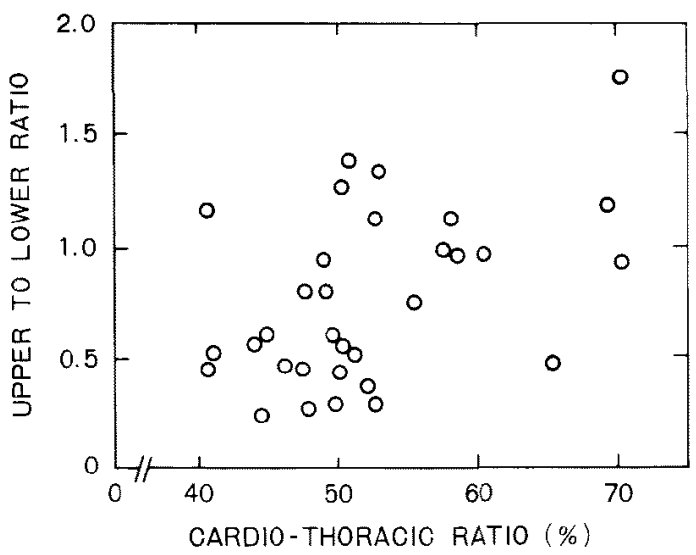

Fig. 14. Relationship of cardiothoracic ratio and U/L. ratio in the upright lung. No significant correlation was observed.

above $20 \mathrm{~mm} . \mathrm{Hg}$ of left atrial mean pressure. There was no significant correlation between $\mathrm{U} / \mathrm{L}$ ratio and cardiothoracic ratio as shown in Fig. 14 . From these results impaired dynamics of pulmonary circulation causing the reduction of blood flow in lower zone of the lung followed by increased blood flow distribution in upper zone were shown to correlate more significantly with left atrial mean pressure than with any other hemodynamic variables.

\section{Discussion}

The recent radioisotope techniques introduced into regional pulmonary blood flow have become widely available and made great progress in this field. In normal distribution of pulmonary blood flow in the upright human lung under the influence of gravitational hydrostatic pressure on pulmonary circulation, relatively little apical blood flow with much basal flow has been shown in 1960 by West et al., ${ }^{3)}$ in 1962 by Ball et al. ' and in 1963 by Anthonisen et al.

Estimation of regional pulmonary blood flow using intravenous injection of $\mathrm{I}^{131}$-MAA which varies in size from $10-50 \mu$. has been shown by Wagner et al. ${ }^{15)}$ as a safe and effective way without any hemodynamic, histological, immunologic and radiation hazard. We have studied the distribution of pulmonary blood flow in various cardiopulmonary disorders by our method, lung profile scanning technique using MAA, as shown in Fig. 1, 2 and 3 since 1964.11), 12),13) MAA-pulmogram obtained in this scanning showing the distribution of pulmonary blood flow was divided into 2 portions per each lung, that is the 
upper half lung and the lower half, and U/L ratio was calculated from upper and lower distribution indices of pulmonary blood flow estimated quantitatively. So that derived $U / L$ ratio did not necessarily represent $U / L$ ratio per unit lung volume but $\mathrm{U} / \mathrm{L}$ ratio of whole lung divided into 2 portions. In MAA technique, except radioactive gas methods, measurement of human regional pulmonary blood flow per unit lung volume was fairly difficult to be performed, because difficulty of inhalation of $\mathrm{I}^{131}$-MAA made volume correction impossible. However, quantitative assessment in 4 portions of lungs such as right, left, upper, and lower was successfully done as shown above.

Effects of hydrostatic pressure in normal distribution of pulmonary blood flow were obviously seen in good agreement with the data described by many investigators. Mechanism of these normal distribution of pulmonary blood flow has been well explained by West et al, ${ }^{31,16), 17)}$

On the other hand, it was reported in 1960 by Dollery and West ${ }^{7)}$ that patients with severe mitral stenosis often showed a higher blood flow through the upper zone of the lung than the lower. Pulmonary arterial flow distribution has been found to be reversed in patients with mitral stenosis.

In 1957, Doyle et al. ${ }^{18)}$ observed that arterial narrowing in patients with mitral stenosis complicated by pulmonary hypertension was most marked at the base and in the midzones, whereas the upper zone arteries were often normal. Steiner ${ }^{19)}$ showed with pulmonary angiograms that the upper zone pulmonary vessels were grossly dilated and the lower zone vessels narrow in patients with mitral stenosis. Harrison ${ }^{20}$ examined the anatomic changes of lungs and confirmed the dilatation of the arteries in the upper zone and constriction of those in the lower. It has been considered from these investigation that anatomic changes of pulmonary vessels may play an important role to cause increased upper to lower ratio. The anatomic changes caused by any physiological and hemodynamic abnormalities was difficult to explain.

Our results demonstrate that increased $\mathrm{U} / \mathrm{L}$ ratio was characteristic in left heart failure group and correlated significantly with left atrial mean pressure $(r=+0.85, p<0.001)$. U/L ratio did not elevate under the level of $10 \mathrm{~mm} . \mathrm{Hg}$ in the left atrial mean pressure. When left atrial mean pressure was over $10 \mathrm{~mm} . \mathrm{Hg}, \mathrm{U} / \mathrm{L}$ ratio was linearly proportional to the left atrial mean pressure. West et al. ${ }^{21}$ evidenced in 1965 that, when the pulmonary venous pressure was raised, increased pulmonary vascular resistance in the lower zone of the isolated suspended dog lung was caused by interstitial perivascular edema.

Perivascular edema around the small arteries of a maximum diameter of about $100 \mu$. was observed histologically in the lower lung frozen with liquid nitrogen. From our results of hemodynamic studies it is obviously considered that the interstitial perivascular edema in the dependent zonc of the lung may 
play a significant role in regulating the vascular resistance of the lower zone in reflecting the left atrial mean pressure. It is enough to explain that a definite duration of the elevated left atrial pressure followed by interstitial perivascular edema of the lower zone would lead to the anatomic changes of pulmonary vasculature in the lower zone.

\section{Acknowledgement}

We wish to thank the following physicians for their participation in this study : O. Suzuki, M. D., K. Katayama, M. D., T. Ohashi, M. D., T. Sekimoto, M. D., and A. Nakajima, M.D.

\section{REFERENCES}

1. Martin, C. J., Cline, F., and Marshall, H.: J. Clin. Invest. 32: 617, 1953.

2. Mattson, S. B. and Carlens, E.: J. Thorac. Surg. 30: 676, 1955.

3. West, J. B. and Dollery, C. T.: J. Appl. Physiol. 15: 405, 1960.

4. Ball, W. G., Stewart, P. B., Newsham, L. G. S., and Bates, D. V.: J. Clin. Invest. 41 : 519, 1962.

5. Dollery, C. T. and Gillam, P. M. S.: Thorax 18: 316, 1963.

6. Anthonisen, N.R. and Milic-Emili, J.: J. Appl. Physiol. 21 : 760, 1966.

7. Dollery, C. T. and West, J. B.: Circulat. Res. 8: 765, 1960.

8. Taplin, G. V., Johnson, D. E., Dore, E. K., and Kaplan, H. S.: J. Nucl. Med. 5: 259, 1964.

9. Wagner, H. N., Sabiston, D. C., McAfee, J. G., Tio, M., Meyer, J. K., and Langan, J. K.: J.A.M.A. 187: 601, 1964.

10. Lopez-Majano, V., Chernick, V., Wagner, H. N., and Dutton, R. E.: Radiology 83: 697, 1964.

11. Sasamoto, H. and Kunieda, T.: Medical Culture 7: 718, 1965 (in Japanese).

12. Sasamoto, H., Hosono, K., Sekimoto, T., Nakajima, A., Sato, S., and Kunieda, T.: Sogo Rinsho 15: 1443, 1966, (in Japanese).

13. Sasamoto, H. and Kunieda, T.: Naika 18: 461, 1966 (in Japanese).

14. Kunieda, T.: Studies on the regional pulmonary blood flow by I ${ }^{131}$-MAA lung profile scanning. Gravitational changes in the distribution of pulmonary blood flow, presented at 6 th Annual Meeting of the Japanese Society of Nuclear Medicine in November, 1966, Tokyo, Japan.

15. Wagner, H. N., Sabiston, D. G., McAfee, J. G., Tow, D.E., and Stern, H. S.: New. Eng. J. Med. 271 : 377, 1964.

16. West, J. B., Dollery, C. T., and Naimark, A.: J. Appl. Physiol. 19: 713, 1964.

17. West, J. B. and Dollery, C. T.: J. Appl. Physiol. 20: 175, 1965.

18. Doyle, A. E., Goodwin, J. F., Harrison, C. V., and Steiner, R. E.: Brit. Heart J. 19: 353, 1957.

19. Steiner, R. E,: Brit. J. Radiol. 31 : 188, 1958.

20. Harrison, C. V.: Brit. J. Radiol. 31: 217, 1958.

21. West, J. B., Dollery, C. T., and Heard, B. E.: Circulat. Res. 17: 191, 1965. 